\title{
Differential Evolution Based Solar Photovoltaic Array Reconfiguration Algorithm for Optimal Energy Extraction during Partial Shading Condition
}

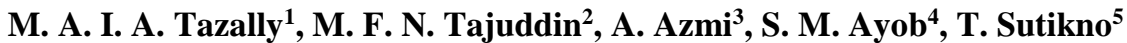 \\ ${ }^{1,2,3}$ School of Electrical Systems Engineering, Universiti Malaysia Perlis, Perlis, Malaysia \\ ${ }^{4}$ School of Electrical Engineering, Faculty of Engineering, Universiti Teknologi Malaysia, Skudai, Malaysia \\ ${ }^{5}$ Department of Electrical Engineering, Faculty of Industrial Tech., Universitas Ahmad Dahlan, Yogyakarta, Indonesia
}

\begin{tabular}{|c|c|}
\hline Article Info & ABSTRACT \\
\hline Article history: & To increase energy yield from an installed photovoltaic (PV) array, \\
\hline Received Jul 21, 2018 & $\begin{array}{l}\text { particularly during partial shading condition (PSC), a new technique based } \\
\text { on reconfigurable PV array interconnection is proposed in this work. The }\end{array}$ \\
\hline Revised Aug 9, 2018 & proposed technique works by dynamically changing the interconnection of \\
\hline Accepted Aug 10, 2018 & $\begin{array}{l}\text { PV modules to form a new configuration using a switching matrix inside the } \\
\text { array. The criteria of good reconfigurable PV array interconnection }\end{array}$ \\
\hline Keyword: & $\begin{array}{l}\text { techniques depend on the efficiency and accuracy of the control algorithm to } \\
\text { optimally reconfigure the PV array to maximize the total output power. }\end{array}$ \\
\hline Differential evolution & Hence, this paper proposes a new control algorithm using differential \\
\hline Partial shading . . . . . & $\begin{array}{l}\text { evolution (DE) for photovoltaic array recontiguration (PVAR). Io verify the } \\
\text { superiority of the proposed algorithm, DE is compared with the particle }\end{array}$ \\
\hline Particle swarm optimization & swarm optimization (PSO) algorithm. Results confirm that DE performs well \\
\hline Photovoltaic & in terms of the amount of energy production during PSC. For all the nine \\
\hline Reconfiguration algorithm & $\begin{array}{l}\text { shading patterns tested on a } 3 \times 3 \mathrm{PV} \text { array, DE yields } 1 \% \text { to } 5 \% \text { more power } \\
\text { than PSO. }\end{array}$ \\
\hline
\end{tabular}

Copyright () 2018 Institute of Advanced Engineering and Science. All rights reserved.

\section{Corresponding Author:}

M. F. N. Tajuddin,

School of Electrical Systems Engineering,

Universiti Malaysia Perlis,

02600 Pauh, Perlis, Malaysia.

Email: faridun@unimap.edu.my

\section{INTRODUCTION}

Environmental health is one of the most crucial problems the world is facing. Thus, a few environmentally friendly solutions have been proposed. A photovoltaic (PV) system is a power-generating system that produces clean energy and is in demand by many countries. Governments of different countries have formed policies and frameworks for renewable energy, especially those that use PV technology. These policies encourage the use of PV solutions instead of coal, natural gas, and petroleum, which emit greenhouse gases [1-3]. However, PV exhibits low efficiency in converting light to electrical energy due to mismatch losses. The primary reason for mismatch losses is partial shading condition (PSC) because of overhead clouds, nearby buildings, or any surrounding objects. PSC causes considerable power losses to the PV system [4-7].

Avoiding PSC, especially passing clouds, is close to impossible. Research has proposed several approaches to reduce power losses. Three major ways to mitigate power losses are as follows: (1) improved maximum power point tracking techniques, (2) modified system architectures, and (3) improvised PV array configurations [8-12]. In [13] and [14], the researchers proposed several static configurations and tested their performance. The researchers concluded that total cross-tied (TCT) configuration was the best configuration based on its performance compared with the other common configurations, such as series-parallel, bridge- 
linked, and honeycomb. Power loss was reduced in the TCT configuration because of the cross-tie $\left(\mathrm{C}_{\mathrm{T}}\right)$ that connects across each junction as an alternate path for the current to flow through the PV array.

[15] and [16] improved the PV array configuration method into the PV array reconfiguration (PVAR). PVAR forms a new configuration based on the optimal output power under static and nonstatic PSC by changing the connection or physical movement of the PV modules. Sanseverino et al. proposed PVAR control by switching to the matrix that is based on irradiance equalization method. This method reduced the multiple peaks of power-voltage $(P-V)$ and current-voltage $(I-V)$ curves caused by bypassing diodes in the $\mathrm{PV}$ array to a single peak. However, this method is not precise because the irradiance values of each PV module are estimated by an equation and not by an irradiance meter, which provides a high chance of obtaining accurate readings. Furthermore, implementing this method entails a high cost because current and voltage sensors are required for each PV module [17]. Babu T.S. et al. implemented particle swarm optimization (PSO) algorithm to control and optimize the switching matrix of PVAR with an array size of 9 $\times 9$. The objective function of the PSO algorithm is irradiance equalization, which utilizes an equation to estimate the irradiance values. Although this work used the PSO algorithm as the optimization method, the PVAR does not yield the optimal energy because the size of the array after reconfiguration is still fixed at $9 \times$ 9, and the irradiance values are not comparable with the real values [18]. Ramaprabha proposed a PSO algorithm that is also implemented in PVAR and whose objective function is power maximization. The variable of the objective function is the current value of the PV array. Nevertheless, the accuracy of the PSO algorithm in this work is not constant, and it does not optimally extract the energy [19]. Consequently, some improvements have been made in this work by utilizing differential evolution (DE) algorithm in PVAR. The PVAR works by changing the electrical connection between the PV modules regardless of its physical position. The objective function of DE in this work is similar in [19]. The objective function can be achieved by changing the switches of the modules. Only one of each current and voltage sensors is needed to measure the output power of each population during the optimization process. The proposed DE-based PVAR is compared with PSO to analyze the performance of both algorithms. Both algorithms are tested on a $3 \times 3 \mathrm{PV}$ array under 9 shading patterns by using MATLAB/Simulink® software.

\section{BASIC PRINCIPLE}

This work uses MATLAB/Simulink® software to develop the DE-based PVAR. To implement PVAR, a suitable model of PV cell needs to be developed in the software. Then, the PV cells are connected to form the PV modules and an array. Normally, 36 PV cells are connected in series to form a PV module. In this work, a single-diode PV model is used to model the simple yet accurate characteristics of PV cells. The single-diode model provides an excellent qualitative prediction of PS and mismatch effects [9, 20]. Figure 1 shows the equivalent circuit of the single-diode PV model.

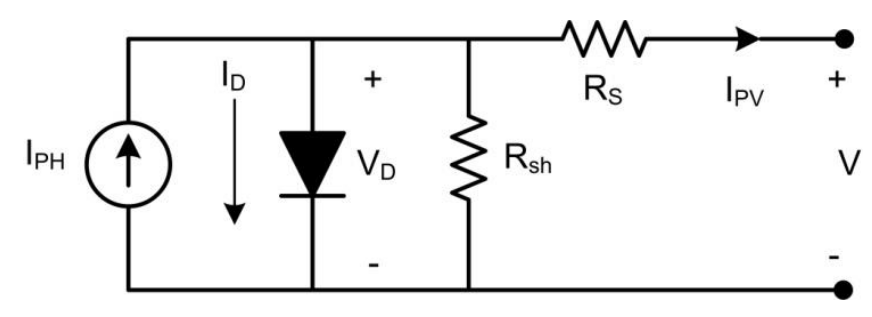

Figure 1. PV cell equivalent circuit

$$
I_{P V}=I_{P H}-I_{o}\left[\exp \left(\frac{V_{P V}+R_{s} I_{P V}}{a V_{T}}\right)-1\right]-\left[\frac{\left(V_{P V}+I_{P V} R_{S}\right)}{R_{s h}}\right]
$$

where $I_{P H}$ : light-generated current,

$I_{P V}$ : current generated by incident light,

$I_{0}:$ reverse saturation current,

$R_{s}$ : series resistance,

$R_{s h}$ : parallel resistance,

$a$ : diode ideality constant,

$V$ : thermal voltage of the PV module with $N_{S}$ 
cells connected in the series $\left(N_{s} k T / q\right)$

$q$ : electron charge $\left(1.60217646 \times 10^{-19}\right)$, and

$k$ : Boltzmann constant $\left(1.3806503 \times 10^{-23} \mathrm{~J} / \mathrm{K}\right)$.

The equation for the single PV model is extracted from Equation (1). The light-generated current $I_{P H}$ depends on the short circuit current in the standard test condition $I_{S C, S T C}$, the irradiance experienced by the surface of PV module $G$, and the irradiance of the standard test condition $G_{S T C}$, as stated in (2)

$$
I_{P H}=\left(I_{S C, S T C}+K_{i} \Delta T\right) \frac{G}{G_{S T C}} \frac{R_{s h}+R_{s}}{R_{s h}}
$$

$K_{i}$ is the temperature coefficient of the short-circuit current and $\Delta T=T-T_{S T C}$, where $\mathrm{T}$ is the surrounding temperature of the PV module. The conditions that have been set for standard test condition (STC) are $T_{S T C}=25^{\circ} \mathrm{C}$ and $G_{S T C}=1,000 \mathrm{~W} / \mathrm{m}^{2}$. As indicated by Equation (2), the performance of PV is susceptible to the irradiance and temperature level. In the case of PSC, the observation on the irradiance and temperature levels is set constant according to STC. The parameters of the PV cell for this paper are based on the National Renewable Energy Laboratory system. This work employed 9 PV modules (API156P-230) manufactured by Advance Solar Hydro Wind Power.

PSC can cause the hotspot effect on the PV module, thereby causing the PV module to overheat and become damaged entirely. Adding a bypass diode in the anti-parallel connection with the PV module can reduce the effect, as shown in Figure 2. PV1 is the module that experiences PSC. Hence, the bypass diode creates a new path for the current produced by the non-shaded PV modules to flow across the string.

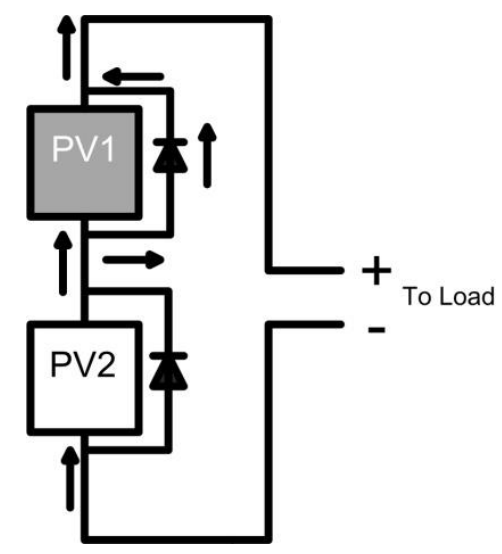

Figure 2. PV modules connected with bypass diode

\section{DEVELOPMENT OF THE PV ARRAY RECONFIGURATION (PVAR)}

To build a high-performance PVAR circuit, the basic topology of the circuit should be selected based on static configuration. Most researchers proved that the TCT configuration is the best static configuration under PSC with less power loss [21, 22]. Consequently, the PVAR connection in this work is developed based on a TCT topology. Each series of connected PV modules is connected with a cross-tie (CT) across each junction. Figure 3 shows the wiring diagram of PVAR that implements a switching matrix that is controlled by a digital microcontroller unit. The PV modules in the PVAR are represented by PV1 to PV9.

The green lines show the connection of the microcontroller unit to each set of the switching matrix. The microcontroller is also connected to the voltage and current sensors. Hence, the microcontroller can determine the output power of the PVAR during the reconfiguration process. Moreover, the switching matrix rearranged the electrical connection of the PV modules within three rows in the PVAR to form the new reconfiguration. The PV modules in the PVAR switched the electrical connections to the first row when the microcontroller unit set the command " 1 " to the switching matrix, then to the second row when the command is set to " 2 ," and then to the third row when the command is set to " 3 ."

Figure 4 illustrates how the switching matrix of PVAR changed the electrical connection between the PV modules. PV7 and PV9 are shaded. The initial physical positions and electrical connections of PV7 
and PV9 are in the first and third rows, respectively. After the microcontroller unit set the command to the switching matrix based on the maximum output power, the electrical connections between PV7 and PV9 are changed to the second and first rows, respectively, without altering their physical positions.

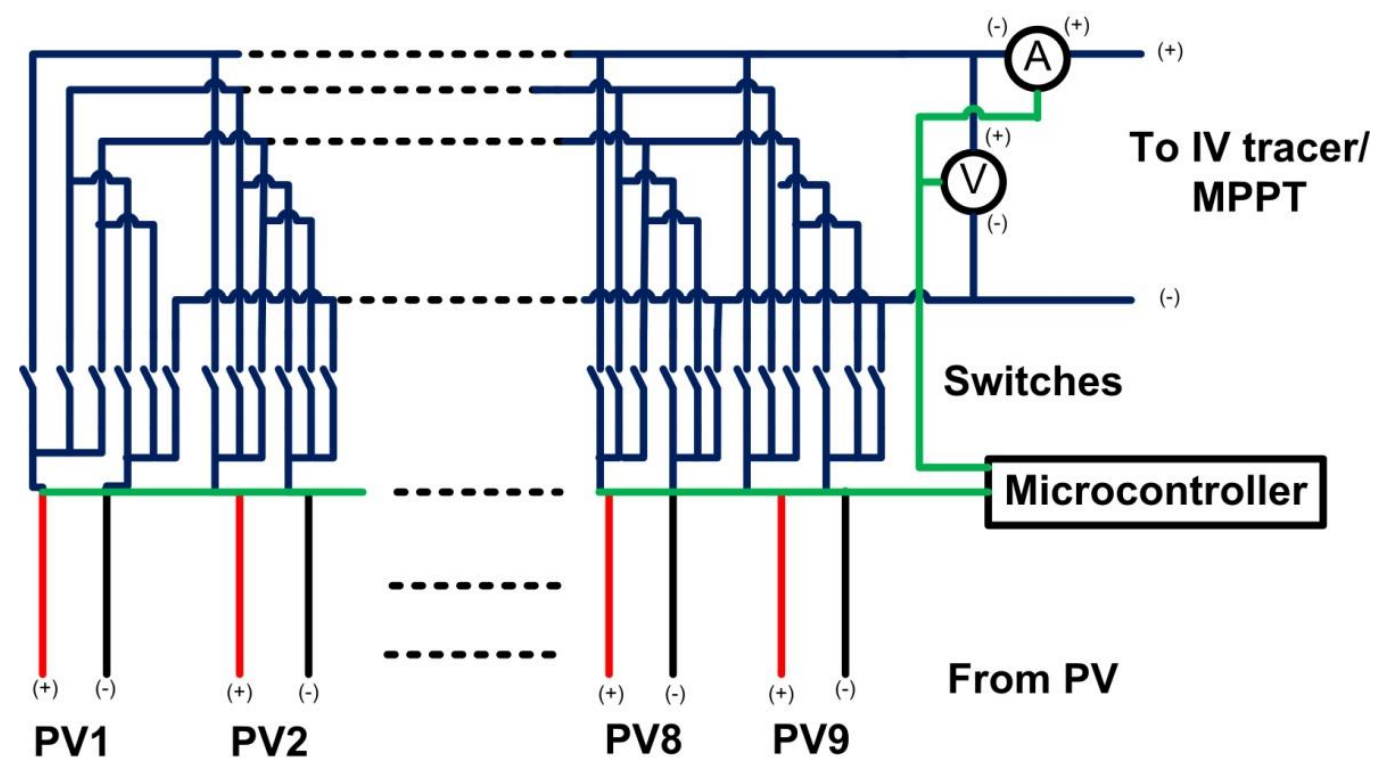

Figure 3. Wiring diagram of the PVAR circuit
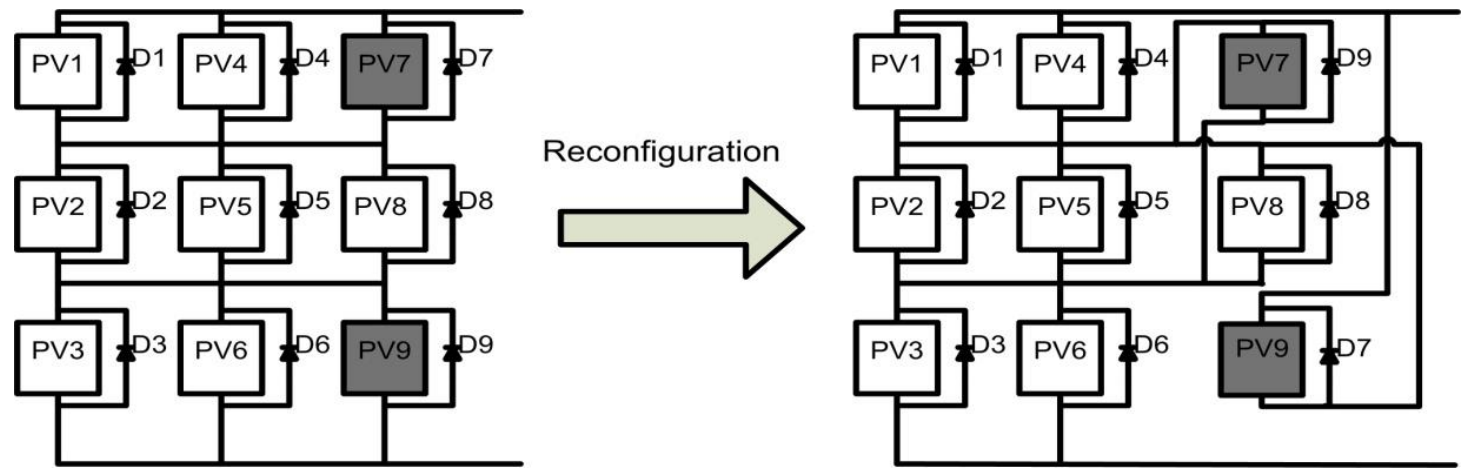

Figure 4. PVAR circuit before and after reconfiguration

\section{DIFFERENTIAL EVOLUTION BASED PVAR}

Solving for the switching matrix of the PV array is complicated under certain shading patterns, and several iterations are needed to obtain the result. To solve this problem and to reach the optimum power from the PV array, the DE algorithm is employed to reconfigure the switching matrix. DE was introduced in [23] and is one of the most powerful population-based optimization algorithms. DE is a simple algorithm that requires few control parameters, and it works by creating a new candidate solution under a different equation with different techniques for a problem that requires maintaining the size of a population. The new candidate and the existing solutions are compared to produce the best fitness for the objective function of the problem. The chosen solution stays in the population until the next preferred solution takes place.

This algorithm aims to optimize a problem or an objective function $\mathrm{X}$. The objective function of the $\mathrm{DE}$ algorithm is the maximum output power of PVAR. The population $\mathrm{P}$ in DE has individuals of the population that are NP real-valued parameter vectors. The potential solution candidate is formed through the individuals of the population and can be described as (3)

$$
P^{G}=X_{i}^{G}, i=1,2, \ldots, N P, G=1,2, \ldots, G_{\max }
$$


The DE population size is set at 10, and each individual in the population has its own dimension size, which is set to 9 because the PVAR circuit has 9 PV modules. The population works as an individual that produces the potential candidate in solving the optimization problem. Furthermore, the generation $G$ is set at 25, wherein 10 individuals in the population will iterate 25 times. As mentioned in the previous section, the microcontroller in the PVAR circuit needs to set the commands "1," "2," and " 3 ." Therefore, the constraints set in this work are 1 for the lower boundary and 3 for the upper boundary based on Equation (4).

$$
L \leq X \leq H: L, H \in R^{D}
$$

Given that DE is a population-based algorithm, the initialization of the population is the first step during optimization. The initial population $P^{0}$ for the first generation of the vector is randomly generated according to Equation (5)

$$
P^{0}=x_{i, j}^{0}=\operatorname{rand}(0,1) \cdot\left(x_{j, U}-x_{j, L}\right)+x_{j, L}
$$

The function of rand $(0,1)$ generates a random number within the range $0-1$, where $x_{i, j}^{0}$ is the vector of the initial generation, $\mathrm{i}$-th individual population, and $\mathrm{j}$-th control variables or dimension that is generated within the constraint of upper limit $x_{j, U}$ and lower limit $x_{j, L}$.

Mutation is an important process in an evolution-based algorithm. The mutation process is illustrated in Figure 5. Mutant vector $V_{i}^{G}$ is produced during this process to form a new candidate solution for the existing solution candidate, which is known as target vector $X_{i}^{G}$. Five mutation strategies can be used in DE to generate $V_{i}^{G}$ in each generation. However, only one commonly used strategy is utilized in this work, which is shown in Equation (6), and the differential constant is set as $F=0.9$.

$$
\mathrm{DE} / \mathrm{rand} / 1 V_{i}^{G}=x_{r 1}^{G}+F \cdot\left(x_{r 2}^{G}-x_{r 3}^{G}\right)
$$

Crossover operation is performed to shuffle the component in the mutant and target vectors, thereby producing a chosen vector that is known as trial vector $U_{i}^{G}$. The scheme of the crossover rate CR is set as 0.5 in this work.

Then, the trial and target vectors go through the process of choosing the vector that will survive in the next iteration. The selection is based on the maximum output power of the PVAR. After the iteration of the generation is completed, the best combination cases will be selected as the solution for the objective function. The whole process of DE-based PVAR is explained in Figure 6.

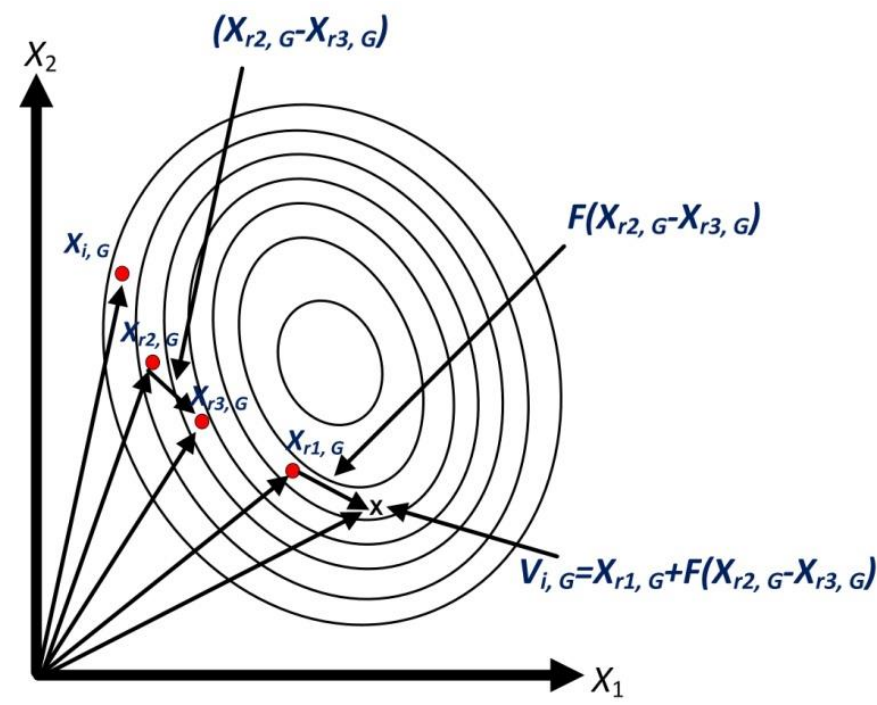

Figure 5. Illustration of DE mutant vector (DE/rand/1) 


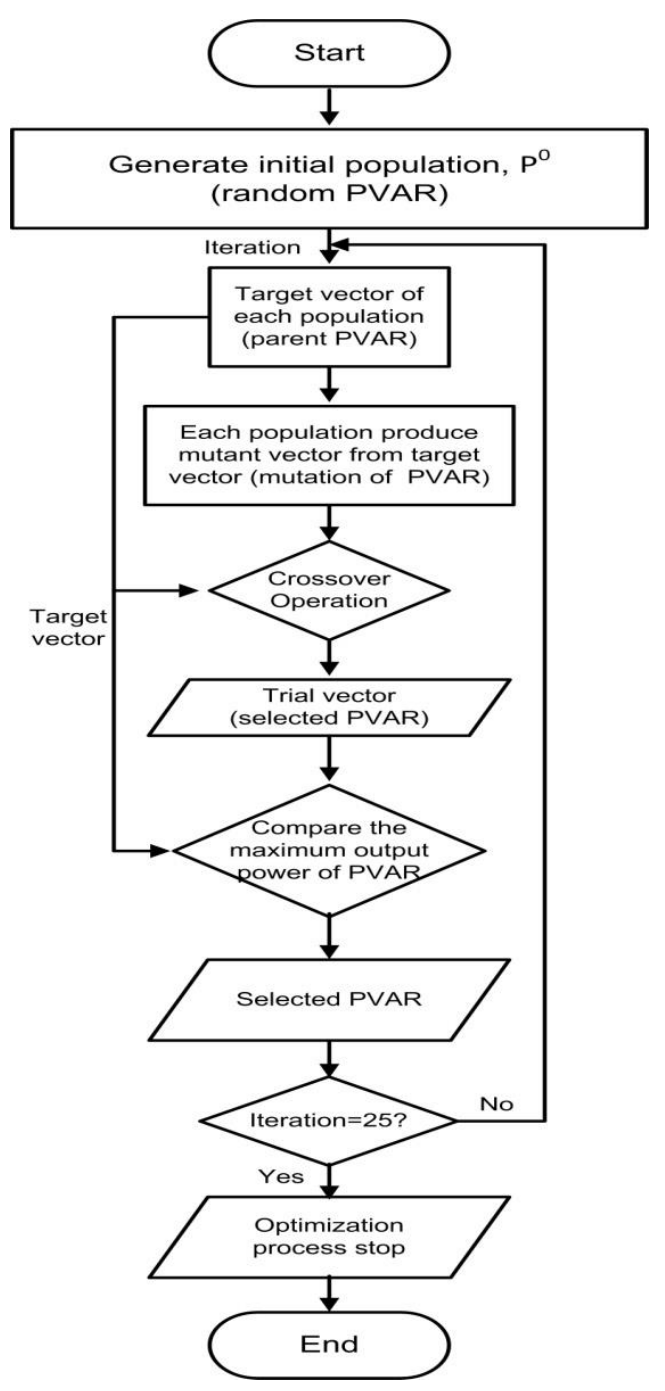

Figure 6. Flowchart of the DE optimization process

\section{PERFORMANCE OF DE AND PSO BASED PVAR}

In this work, the proposed DE-based PVAR is compared with the PSO algorithm to observe their effectiveness and performance. Similar to DE, PSO is a population-based algorithm. Thus, comparing both algorithms in terms of their fitness and accuracy in optimizing PVAR output power under PSC is reasonable. The population, dimension, and generation for both algorithms are set similarly. The performances of DEand PSO-based PVAR are tested on nine shading patterns to simulate the real PSC, as shown in Figure 7. The PV modules in the PVAR are set with different irradiance values of 300, 500, 700, and 1,000 W/m2. The maximum output powers of the fully irradiated patterns for both algorithms are similar. Therefore, only eight remaining patterns will be observed. Otherwise, the fully irradiated pattern becomes a reference pattern.

The performances of DE and PSO are observed based on the percentages of power losses (\%PL). To analyze \%PL, the maximum output power of the DE- and PSO-based PVARs under the observed patterns (Pmax) are compared with the output power of the reference pattern (Pmaxref), as stated in Equation (7)

$$
\% P L=\frac{P \max -P \max _{r e f}}{P \max _{r e f}} \times 100 \%
$$

The fitness of the algorithms is analyzed, and the result is shown in the next section. Each generation produced a selected PVAR with its corresponding output power, and the maximum output power is assumed to have been achieved when a solution converges. The best algorithm should converge faster with high accuracy and maximum power. 


\begin{tabular}{|c|c|c|}
\hline $\mathrm{PV}$ & $\mathrm{PV}$ & $\mathrm{PV}$ \\
1 & 4 & 7 \\
\hline $\mathrm{PV}$ & $\mathrm{PV}$ & $\mathrm{PV}$ \\
2 & 5 & 8 \\
\hline $\mathrm{PV}$ & $\mathrm{PV}$ & $\mathrm{PV}$ \\
3 & 6 & 9 \\
\hline
\end{tabular}

1. Fully Irradiated
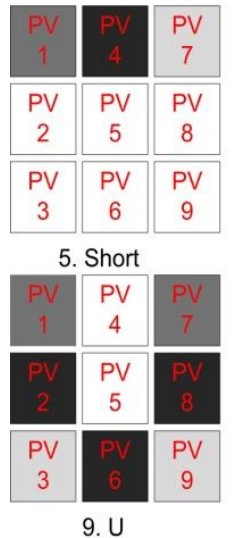

$300 \mathrm{~W} / \mathrm{m}^{2}$

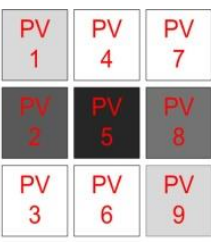

2. Diagonal and Long

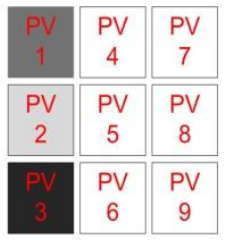

6. Long

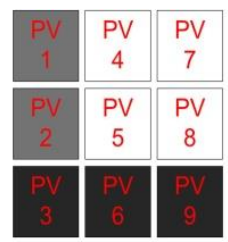

3. Short and Long

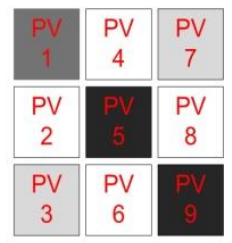

7. Cross

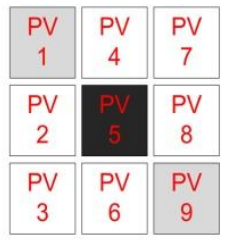

4. Diagonal

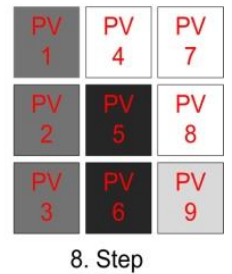

$500 \mathrm{~W} / \mathrm{m}^{2}$

$700 \mathrm{~W} / \mathrm{m}^{2}$

$1000 \mathrm{~W} / \mathrm{m}^{2}$

Figure 7. Shading patterns

\section{RESULTS AND DISCUSSION}

The performance of the proposed DE-based PVAR is observed from the result of the analyses. After 25 generations of DE and PSO algorithms are completed, the $P-V$ characteristics of both algorithms are compared to analyze the power loss, as illustrated in Figure 8. The \%PL of the DE-based PVAR on the diagonal and long, short, long, cross, step, and U patterns are lower than that of the PSO-based PVAR. The remaining patterns show that the \%PL for both algorithms is similar. To summarize, DE-based PVAR is the ideal technique to yield energy from the PV array because it produces the highest Pmax and has low power losses under most PS patterns.

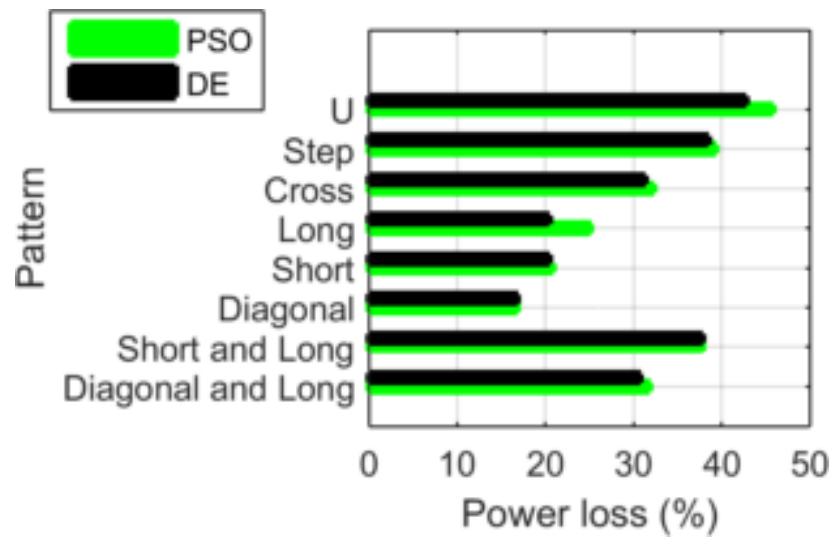

Figure 8. Power loss percentages

Table 1 shows that the fastest maximum output power achieved by DE-based PVAR is at Generation $=7$ during the short pattern. However, PSO converges faster at Generation=1 under the step pattern. For all patterns, PSO converges to the maximum output power earlier than DE. However, its solution is not optimal because the output power is not at maximum. Thus, DE has better accuracy and optimum output power. PSO converges faster but lacks accuracy and has a tendency to be trapped at local peaks. Therefore, DE is considered the most efficient algorithm to be used as an optimizer for PVAR, given that the 
primary objective of this work is to extract the optimal output power from the PV array during PS occurrences.

Table 1. Number Of Generations To Achieve Steady State

\begin{tabular}{lcc}
\hline Pattern & $\begin{array}{c}\text { Number of generations } \\
\text { to achieve steady state } \\
\text { for DE }\end{array}$ & $\begin{array}{c}\text { Number of generations } \\
\text { to achieve steady state } \\
\text { for PSO }\end{array}$ \\
\hline Diagonal and Long & 18 & 4 \\
Short and Long & 23 & 3 \\
Diagonal & 19 & 3 \\
Short & 7 & 4 \\
Long & 11 & 7 \\
Cross & 20 & 3 \\
Step & 12 & 1 \\
U & 13 & 6 \\
\hline
\end{tabular}

Figure 9 shows the representation of PVAR after the DE algorithm performed the optimization operation. As stated in the previous section, the physical positions of the PV modules remain unchanged. Otherwise, the electrical connections of the PV modules are changed between the rows in the PVAR to extract the optimal output power. The results from the reconfiguration also proved that the irradiance equilibrium technique, as mentioned in the literature, is impractical. The technique should have more options for PVAR to optimize the reconfiguration and find the best configuration. Lastly, DE-based PVAR is simple, accurate, practical, and consistent in extracting solar energy under PSC.
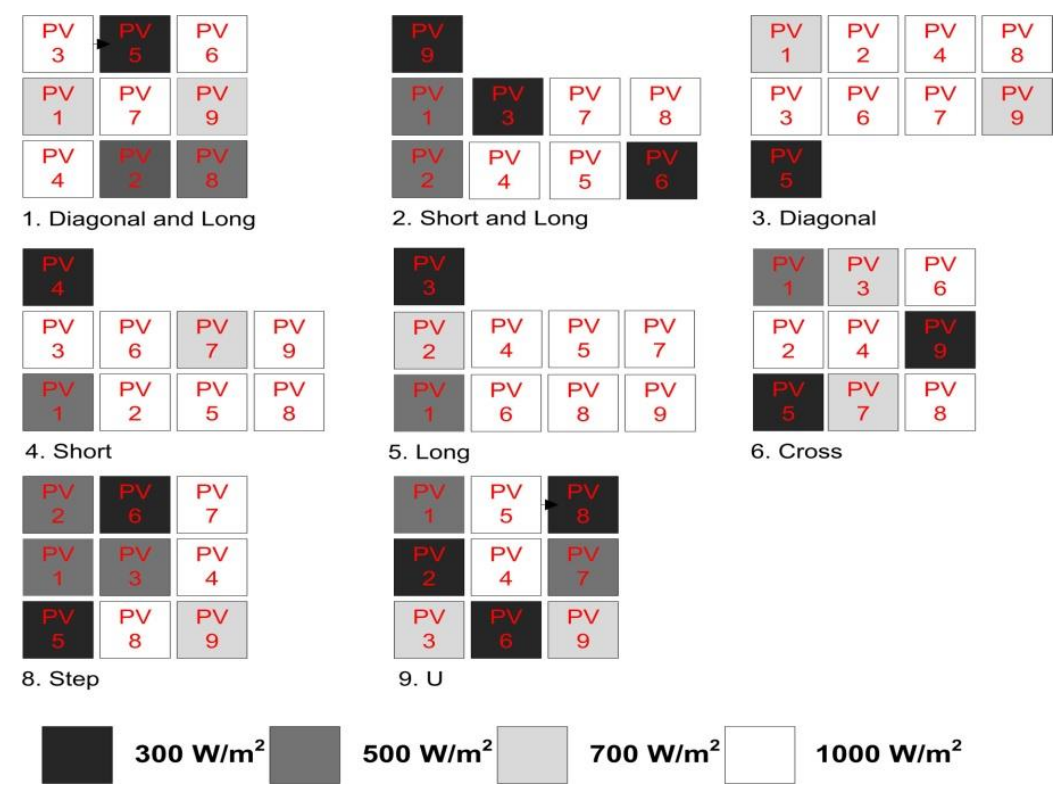

2. Short and Long
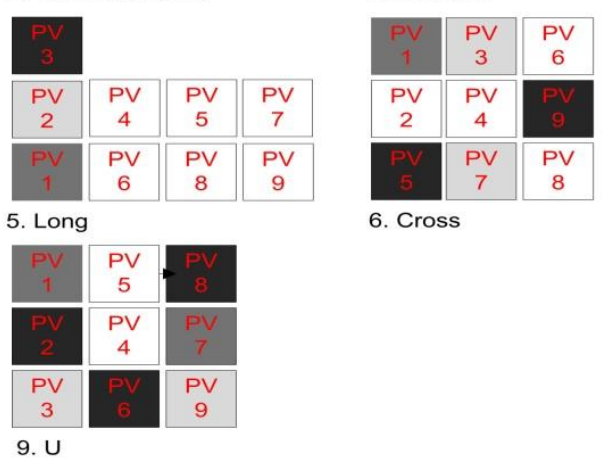

6. Cross

$500 \mathrm{~W} / \mathrm{m}^{2}$

$700 \mathrm{~W} / \mathrm{m}^{2}$

$1000 \mathrm{~W} / \mathrm{m}^{2}$

Figure 9. Representation of PVAR after DE optimization operation

\section{CONCLUSION}

The objective of this work to yield maximum energy from a partially shaded PV array has been achieved successfully. DE-based PVAR performs well, as proven by various PS patterns. DE-based PVAR extracted more power than PSO-based PVAR and static configurations. In addition, DE produced low power losses, thereby helping to maintain the payback period for PV investors. DE-based PVAR is simple and easy to implement in practice. The PVAR circuit is connected to the $I-V$ tracer to record the data. Furthermore, the experiment can be conducted under a real irradiance value and PSC. Moreover, DE-based PVAR increases awareness of the use of green energy. This study is expected to encourage more investors to show interest in the PV industry. 


\section{ACKNOWLEDGEMENTS}

The authors would like to thank Universiti Malaysia Perlis and Ministry of Education (MOE) Malaysia for providing the facilities and financial support (Fundamental Research Grant Scheme (FRGS) under a grant number of FRGS/1/2015/TK10/UNIMAP/03/2.

\section{REFERENCES}

[1] M. Azhar Khan, M. Zahir Khan, K. Zaman, and L. Naz, "Global estimates of energy consumption and greenhouse gas emissions," Renewable and Sustainable Energy Reviews, vol. 29, pp. 336-344, 2014.

[2] S. R. Pendem and S. Mikkili, "Modelling and performance assessment of PV array topologies under partial shading conditions to mitigate the mismatching power losses," Solar Energy, vol. 160, pp. 303-321, 2018/01/15/ 2018.

[3] M. F. N. Tajuddin, N. A. Rahim, I. Daut, B. Ismail, and M. F. Mohammed, "State space averaging technique of power converter with digital PID controller," in TENCON 2009 - 2009 IEEE Region 10 Conference, 2009, pp. 1-6.

[4] M. Dhimish, V. Holmes, B. Mehrdadi, M. Dales, and P. Mather, "PV output power enhancement using two mitigation techniques for hot spots and partially shaded solar cells," Electric Power Systems Research, vol. 158, pp. $15-25,2018 / 05 / 01 / 2018$

[5] M. A. I. A. Tazally, M. F. N. Tajuddin, A. Azmi, M. U. Maaz, S. Saravan, P. Sanjeevikumar, et al., "Peak prediction method of maximum power point for series-parallel photovoltaic array under partial shading condition," in 2017 Second International Conference on Electrical, Computer and Communication Technologies (ICECCT), 2017, pp. 1-6.

[6] M. A. M. Ramli, S. Twaha, K. Ishaque, and Y. A. Al-Turki, "A review on maximum power point tracking for photovoltaic systems with and without shading conditions," Renewable and Sustainable Energy Reviews, vol. 67, pp. 144-159, 1// 2017.

[7] C. Rahmann, V. Vittal, J. Ascui, and J. Haas, "Mitigation Control Against Partial Shading Effects in Large-Scale PV Power Plants," IEEE Transactions on Sustainable Energy, vol. 7, pp. 173-180, 2016.

[8] M. F. N. Tajuddin, S. M. Ayob, and Z. Salam, "Global maximum power point tracking of PV system using dynamic population size differential evolution (DynNP-DE) algorithm," in Energy Conversion (CENCON), 2014 IEEE Conference on, 2014, pp. 254-259.

[9] M. F. N. Tajuddin, S. M. Ayob, Z. Salam, and M. S. Saad, "Evolutionary based maximum power point tracking technique using differential evolution algorithm," Energy and Buildings, vol. 67, pp. 245-252, 2013.

[10] M. F. N. Tajuddin, S. M. Ayob, and Z. Salam, "Tracking of maximum power point in partial shading condition using differential evolution (DE)," in Power and Energy (PECon), 2012 IEEE International Conference on, 2012, pp. 384-389.

[11] S. Pareek and R. Dahiya, "Enhanced power generation of partial shaded photovoltaic fields by forecasting the interconnection of modules," Energy, vol. 95, pp. 561-572, 2016.

[12] M. L. Orozco-Gutierrez, G. Spagnuolo, J. M. Ramirez-Scarpetta, G. Petrone, and C. A. Ramos-Paja, "Optimized Configuration of Mismatched Photovoltaic Arrays," IEEE Journal of Photovoltaics, vol. PP, pp. 1-11, 2016.

[13] A. Tabanjat, M. Becherif, and D. Hissel, "Reconfiguration solution for shaded PV panels using switching control," Renewable Energy, vol. 82, pp. 4-13, 2015.

[14] M. Z. S. El-Dein, M. Kazerani, and M. M. A. Salama, "Optimal Photovoltaic Array Reconfiguration to Reduce Partial Shading Losses," Sustainable Energy, IEEE Transactions on, vol. 4, pp. 145-153, 2013.

[15] J. D. Bastidas-Rodriguez, C. A. Ramos-Paja, and A. J. Saavedra-Montes, "Reconfiguration analysis of photovoltaic arrays based on parameters estimation," Simulation Modelling Practice and Theory, vol. 35, pp. 50-68, 2013.

[16] S. R. Potnuru, D. Pattabiraman, S. I. Ganesan, and N. Chilakapati, "Positioning of PV panels for reduction in line losses and mismatch losses in PV array," Renewable Energy, vol. 78, pp. 264-275, 2015.

[17] E. R. Sanseverino, T. N. Ngoc, M. Cardinale, V. Li Vigni, D. Musso, P. Romano, et al., "Dynamic programming and Munkres algorithm for optimal photovoltaic arrays reconfiguration," Solar Energy, vol. 122, pp. 347-358, 2015.

[18] T. S. Babu, J. P. Ram, T. Dragičević, M. Miyatake, F. Blaabjerg, and N. Rajasekar, "Particle Swarm Optimization Based Solar PV Array Reconfiguration of the Maximum Power Extraction Under Partial Shading Conditions," IEEE Transactions on Sustainable Energy, vol. 9, pp. 74-85, 2018.

[19] R. Ramaprabha, "Selection of an optimum configuration of solar PV array under partial shaded condition using particle swarm optimization," International Journal of Electrical, Computer, Energetic, Electronic and Communication Engineering, vol. 8, pp. 89-96, 2014.

[20] M. F. N. Tajuddin, N. H. Ghazali, T. C. Siong, and N. Ghazali, "Modelling and simulation of modified unipolar PWM scheme on a single phase DC-AC converter using PSIM," in Research and Development (SCOReD), 2009 IEEE Student Conference on, 2009, pp. 328-331.

[21] N. Belhaouas, M. S. A. Cheikh, P. Agathoklis, M. R. Oularbi, B. Amrouche, K. Sedraoui, et al., "PV array power output maximization under partial shading using new shifted PV array arrangements," Applied Energy, vol. 187, pp. 326-337, 2/1/ 2017.

[22] F. Belhachat and C. Larbes, "Modeling, analysis and comparison of solar photovoltaic array configurations under partial shading conditions," Solar Energy, vol. 120, pp. 399-418, 2015.

[23] R. Storn and K. Price, "Differential Evolution: A Simple and Efficient Adaptive Scheme for Global Optimization over Continuous Spaces," ICSI, USA, Tech. Rep. TR-95-012, 1995. 